\title{
BMJ Open Hospital bed occupancy rate is an independent risk factor for COVID-19 inpatient mortality: a pandemic epicentre cohort study
}

\author{
Francesco Castagna (D) ,, Xiaonan Xue, ${ }^{3}$ Omar Saeed, ${ }^{1,2}$ Rachna Kataria, ${ }^{4}$ \\ Yoram A Puius, ${ }^{1,5}$ Snehal R Patel, ${ }^{1,2}$ Mario J Garcia, ${ }^{1,2}$ Andrew D Racine, ${ }^{1,6}$ \\ Daniel B Sims, ${ }^{1,2}$ Ulrich P Jorde ${ }^{1,2}$
}

To cite: Castagna F, Xue $X$, Saeed 0, et al. Hospital bed occupancy rate is an independent risk factor for COVID-19 inpatient mortality: a pandemic epicentre cohort study. BMJ Open 2022;12:e058171. doi:10.1136/ bmjopen-2021-058171

- Prepublication history and additional supplemental material for this paper are available online. To view these files, please visit the journal online (http://dx.doi.org/10.1136/ bmjopen-2021-058171)

Received 09 0ctober 2021 Accepted 26 January 2022

Check for updates

(c) Author(s) (or their employer(s)) 2022. Re-use permitted under CC BY-NC. No commercial re-use. See rights and permissions. Published by BMJ.

For numbered affiliations see end of article.

Correspondence to

Dr Ulrich P Jorde;

ujorde@montefiore.org

\section{ABSTRACT}

Introduction COVID-19 first struck New York City in the spring of 2020, resulting in an unprecedented strain on our healthcare system and triggering multiple changes in public health policy governing hospital operations as well as therapeutic approaches to COVID-19. We examined inpatient mortality at our centre throughout the course of the pandemic. Methods This is a retrospective chart review of clinical characteristics, treatments and outcome data of all patients admitted with COVID-19 from 1 March 2020 to 28 February 2021. Patients were grouped into 3-month quartiles. Hospital strain was assessed as per cent of occupied beds based on a normal bed capacity of 1491 . Results Inpatient mortality decreased from $25.0 \%$ in spring to $10.8 \%$ over the course of the year. During this time, use of remdesivir, steroids and anticoagulants increased; use of hydroxychloroquine and other antibiotics decreased. Daily bed occupancy ranged from $62 \%$ to $118 \%$. In a multivariate model with all year's data controlling for demographics, comorbidities and acuity of illness, percentage of bed occupancy was associated with increased 30-day in-hospital mortality of patients with COVID-19 (0.7\% mortality increase for each $1 \%$ increase in bed occupancy; HR 1.007, Cl 1.001 to $1.013, \mathrm{p}=0.004$ ) Conclusion Inpatient mortality from COVID-19 was associated with bed occupancy. Early reduction in epicentre hospital bed occupancy to accommodate acutely ill and resource-intensive patients should be a critical component in the strategic planning for future pandemics.

\section{INTRODUCTION}

COVID-19 was declared a global pandemic by the WHO on 11 March 2020. ${ }^{1}$ In the USA, after a cluster of cases reported from Washington state, ${ }^{2}$ New York State quickly became the initial epicentre of this pandemic, with over 1.27 million of cases to date and over 50000 fatalities, with the highest concentration in the Bronx and Queens boroughs of New York City. ${ }^{3}$ Montefiore Einstein, with its three principal teaching hospitals and combined adult bed capacity of 1491 , is the primary healthcare provider for the large,
Strengths and limitations of this study

This is a large cohort study with 7390 patients with COVID-19.

- This is a longitudinal analysis over 1 year of management and hospital policy changes.

- The study analyses mortality changes after adjustment for different therapies and clinical parameters.

- The study identified the association between level of hospital system stress and mortality, with important public health ramifications.

Data on most recent variants were not included.

nearly 1.5 million diverse population of the Bronx $^{4}$ and experienced a 'first wave' of COVID-19 admissions in the spring of 2020, ${ }^{3}$ followed by a significant reduction of cases until a second surge in hospitalisations was noted in the winter of 2020. Throughout the course of the year, multiple public health measures, including those adapting hospital operation to a disaster-level pandemic, such as cancellation of all elective procedures and waiver of state-specific licensing for healthcare providers, were put in place. In addition, the understanding of COVID-19 pathophysiology improved, ${ }^{56}$ new treatments were developed,${ }^{7-10}$ parts of the general population ${ }^{11} 12$ as well as hospital personnel developed antibodies after COVID-19 illness, ${ }^{13}$ and our hospital system adapted to and then recovered from crisis mode. ${ }^{14}$ Here, we report the outcomes of patients hospitalised with COVID-19 through 1 year since the first case, focusing on the differences observed between the spring and the winter surges.

\section{METHODS}

Study population

We retrospectively reviewed all adult patients admitted to Montefiore Medical Center with 
a real-time reverse transcription-PCR assay positive for COVID-19 between 1 March 2020 and 28 February 2021. We divided this timeframe into four 3-month seasons based on the northern hemisphere calendar: spring (from 1 March 2020 to 31 May 2020), summer (from 1 June 2020 to 30 August 2020), fall (from 1 September 2020 to 30 November 2020) and winter (1 December 2020 to 28 February 2021).

\section{Data collection}

Medical data including demographic, clinical and laboratory variables were extracted from the electronic medical record system. The primary outcome was 30-day in-hospital mortality.

\section{Statistical analysis}

Continuous variables are displayed as mean $\pm \mathrm{SD}$ or median (25\%-75\% IQR) and compared with the Student's t-test or Wilcoxon rank-sum, as appropriate. Categorical data are presented as per cent and compared by $\chi^{2}$ test. We estimated the cumulative incidence of the primary endpoint in-hospital mortality for each season, treating hospital discharge as a competing event. ${ }^{15}$ To avoid any bias due to differential follow-up length, we censored the follow-up time at 30 days after admission.

A multivariable competing risk proportional hazard model was used to estimate the subdistribution $\mathrm{HR}^{1617}$ for time to in-hospital death. The covariates in the multivariable analyses included factors present in $>90 \%$ of our data set, known to be associated with in-hospital COVID-19 mortality based on prior literature, ${ }^{6} 1819$ or with a univariate association with in-hospital mortality $(\mathrm{p}<0.05)$ and a clinical (relative difference $>5 \%$ ) difference between survivors and non-survivors (online supplemental table 1). These variables included age, sex, body mass index (BMI), vital signs at presentation (temperature, systolic and diastolic blood pressure, heart rate, respiratory rate, pulse oxygen saturation), platelet count, white cell count, potassium, bicarbonate, creatinine, glucose, alanine transaminase, aspartate transaminase, history of hypertension, dyslipidaemia, chronic kidney disease, heart failure, coronary artery disease, asthma/chronic obstructive pulmonary disease, diabetes mellitus and statin use. Additionally, lactic acid level and per cent of hospital bed saturation were forced into the model as markers of illness severity and level of hospital stress, respectively.

Then we focused on examining the difference in in-hospital death between patients admitted in the spring and in the winter, as they represented the two largest and most temporal distant waves of the COVID-19 pandemic occurring before and after public health policies, specific therapeutic approaches and hospital management changes had been implemented. The selection method for covariates is presented in online supplemental table 2.

The proportionality assumption was examined ${ }^{20}$ and no violation was identified. A two-sided $\mathrm{p}<0.05$ was considered statistically significant.

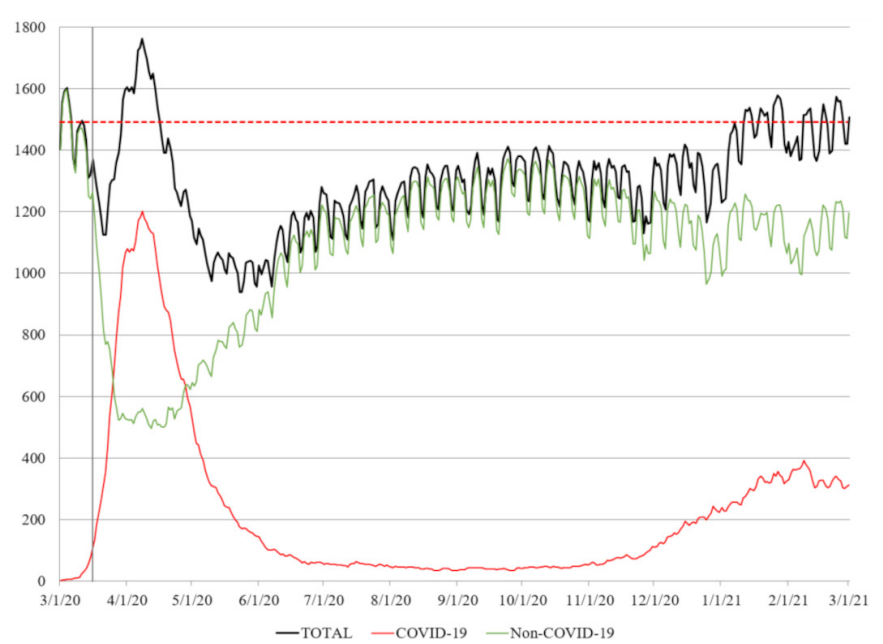

Figure 1 Simultaneously admitted patients. This graph includes hospitalised and admitted patients in the emergency department waiting for a bed. A precipitous decline of nonCOVID-19 admissions began on 16 March 2020 (vertical grey line) coinciding with gubernatorial healthcare-associated directives in New York State. The dotted red line indicates the nominal bed capacity of our institution (1491 beds).

\section{Propensity score analysis}

To fully control the potential differences in patient population and hospital stress between spring and winter patients with COVID-19, we also used propensity score (PS) matching to compare the 30-day in-hospital mortality between spring and winter admissions. The same covariates used for the multivariable competing risk regression were used for PS matching. PS matching was carried out through a 1:1 greedy matching algorithm, with a calliper width of $0.1 \mathrm{SD}$. We then stratified on matched pair in the competing risk regression model. ${ }^{21}{ }^{22}$ Because one-to-one matching led to a reduction in sample size, we used this analysis as a sensitivity analysis.

All statistical analyses was performed with SPSS V.25 and the R packages cmprsk and crrSC (V.3.5; R Foundation for Statistical Computing).

\section{Patient and public involvement}

Given the retrospective nature of our analysis, it was not appropriate or possible to involve patients or the public in the design, or conduct, or reporting or dissemination plans of our research.

\section{RESULTS}

There were 7390 COVID-19-positive adult patients admitted between 1 March 2020 and 28 February 2021 (figure 1). Of these, 4495 patients were admitted during the spring, 264 during the summer, 377 during the fall and 2254 during the winter.

On 8 April 2020, the peak of the spring season, the total number of simultaneously adult patients admitted to our hospital (including those admitted to emergency adult wards at our children's hospital ${ }^{23}$ ) was 1762 (118\% of nominal bed capacity); 1201 of them (68.2\%) 


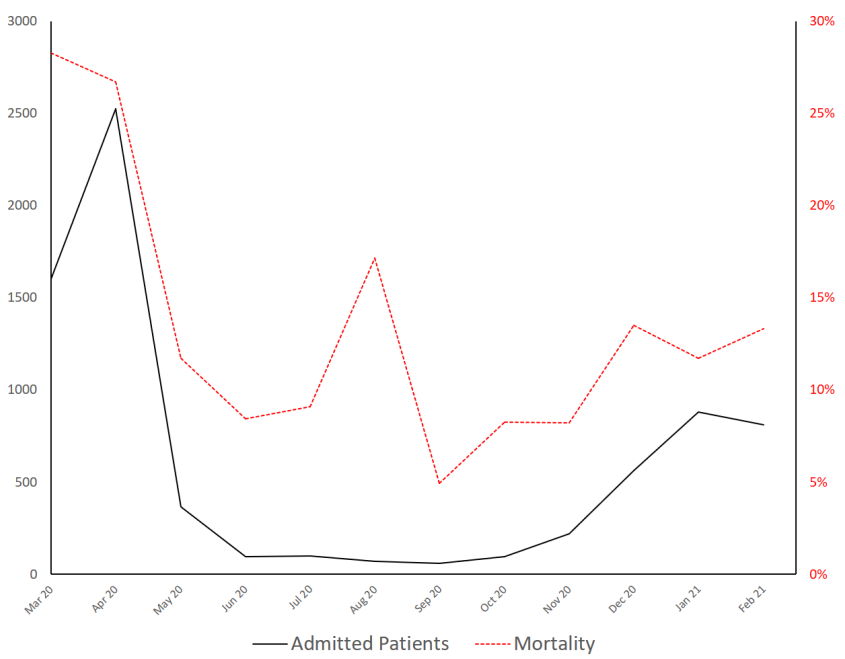

Figure 2 Cumulative monthly admissions (black line, left axis) and mortality (dotted red line, right axis) over the year. were patients with COVID-19. On 8 February 2021, the peak of winter season, 1512 patients (101\% of nominal bed capacity) were admitted to our hospital and 393 of them $(26.0 \%)$ were patients with COVID-19 (figure 1). Following cancellation of elective procedures, bed occupancy decreased to $70 \%$ by the end of the spring season and remained at $90 \%$ until the beginning of the winter season, when the second wave occurred in December 2020. Unadjusted mortality of patients admitted at the beginning of spring, end of spring, beginning of winter and end of winter was $28 \%, 8 \%, 14 \%$ and $13 \%$, respectively (figure 2).

\section{Patient population}

Demographics, medical history and vital signs at arrivals are presented in table 1. Initial laboratory blood tests are presented in online supplemental table 3. Overall, the median age was $66(55-77)$ years, $3835(51.9 \%)$ patients were male and $5519(74.2 \%)$ were of black race and/or

Table 1 Demographics, medical history and vital signs of admitted patients

\begin{tabular}{|c|c|c|c|c|}
\hline & Spring $(n=4495)$ & Summer $(n=264)$ & Fall $(n=377)$ & Winter $(n=2254)$ \\
\hline \multicolumn{5}{|l|}{ 30-day hospital outcome, n (\%) } \\
\hline Still admitted & $194(4.3)$ & $6(2.3)$ & $15(4.0)$ & $103(4.6)$ \\
\hline Died in the hospital & $1124(25.0)$ & $29(11.0)$ & $26(6.9)$ & $258(11.4)$ \\
\hline \multicolumn{5}{|l|}{ Demographics } \\
\hline Male sex, n (\%) & 2377 (52.9) & $138(52.3)$ & $198(52.5)$ & $1122(49.8)$ \\
\hline Black race and/or Hispanic ethnicity, n (\%) & $3345(74.4)$ & $219(83.0)$ & $286(75.9)$ & 1635 (74.2) \\
\hline Body mass index (IQR), $\mathrm{kg} / \mathrm{m}^{2}$ & $28.4(24.6-33)$ & $27.6(22.5-32.7)$ & $28.6(25-34.1)$ & $28.2(24.4-33.1)$ \\
\hline Hospital bed saturation, \% (IQR) & $97.4(86.5-107.6)$ & $81.7(76.3-85.8)$ & $87.6(83.2-90.2)$ & $95.3(91.9-101.8)$ \\
\hline \multicolumn{5}{|l|}{ Medical history, n (\%) } \\
\hline Hyperlipidaemia & $2609(58)$ & $153(58)$ & $199(52.8)$ & $1380(61.2)$ \\
\hline Atrial fibrillation & $449(10)$ & $30(11.4)$ & $35(9.3)$ & $267(11.8)$ \\
\hline Chronic kidney disease & 1406 (31.3) & $70(26.5)$ & $85(22.5)$ & $620(27.5)$ \\
\hline Heart failure & $980(21.8)$ & $72(27.3)$ & $66(17.5)$ & $519(23)$ \\
\hline Coronary artery disease & $1316(29.3)$ & $95(36)$ & $108(28.6)$ & $721(32)$ \\
\hline Asthma/COPD & $1371(30.5)$ & $84(31.8)$ & $98(26)$ & $753(33.4)$ \\
\hline Diabetes mellitus & $2522(56.1)$ & $148(56.1)$ & $187(49.6)$ & $1244(55.2)$ \\
\hline \multicolumn{5}{|l|}{ Vitals at presentation } \\
\hline Temperature (IQR), ${ }^{\circ} \mathrm{C}$ & $37.2(36.8-37.8)$ & 36.9 (36.6-37.2) & $37.1(36.7-37.7)$ & $37.1(36.7-37.7)$ \\
\hline
\end{tabular}

COPD, chronic obstructive pulmonary disease; DBP, diastolic blood pressure; HR, heartrate; SBP, systolic blood pressure. 


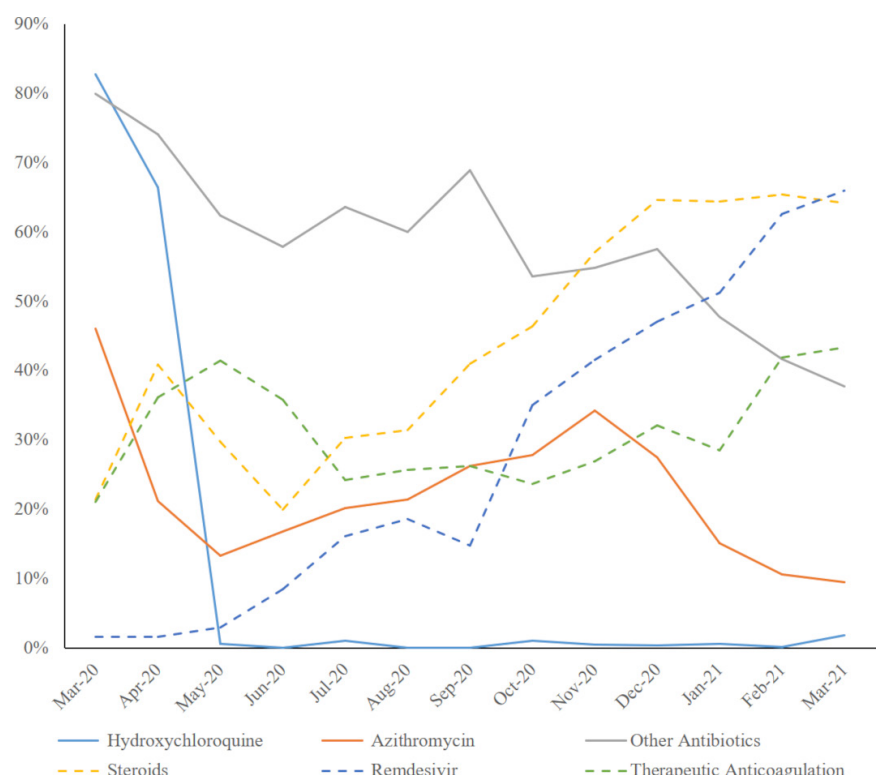

Figure 3 Change in therapies: per cent of patients receiving specific therapies over the year.

Hispanic ethnicity. The median age ranged from 63 years in fall to 67 years in winter. Sex distribution was similar throughout the year. Summer and fall patients had the lowest and the highest BMI: $26.7 \mathrm{~kg} / \mathrm{m}^{2}$ and $28.6 \mathrm{~kg} / \mathrm{m}^{2}$, respectively.

\section{Pharmacotherapy}

Changes in pharmacological approach are presented in online supplemental table 4 and figure 3 .

Spring patients were more likely to receive hydroxychloroquine, azithromycin and other antibiotics. The use of remdesivir substantially increased throughout the year (from less than $2 \%$ during spring to almost $70 \%$ by the end of the winter). Steroids prescription (from 33\% during spring to almost $70 \%$ in February 2021), therapeutic anticoagulation therapy, as well as use of statins, ACE inhibitors (ACE-I) or angiotensin receptor blockers (ARBs) also increased.

\section{Death, intubation and length of stay}

Over the course of a year, 1437 (19.4\%) died while hospitalised. Patients who died were older, had more comorbidities and were more acutely ill, consistent within prior reports on risk factors for death in COVID- $19^{56}$ (online supplemental table 1). The average unadjusted monthly mortality is presented in figure 2. The 30-day in-hospital mortality (figure 4A) was $25.0 \%$ for spring patients, $11.0 \%$ for summer patients, $6.9 \%$ for fall patients and $11.4 \%$ for winter patients $(p<0.001)$. On average, spring patients died 6.4 (3.2-12.9) days after arrival to the emergency department, summer patients 7.2 (3.0-15.7) days after arrival, fall patients 13.4 (8.7-21.6) days after arrival and winter patients $13.3(6.8-20.7)$ days after arrival $(p<0.001)$. The frequency of invasive ventilatory support was higher during the spring, with 892 patients (19.4\%) intubated, vs $27(10.2 \%)$ in summer, $36(9.5 \%)$

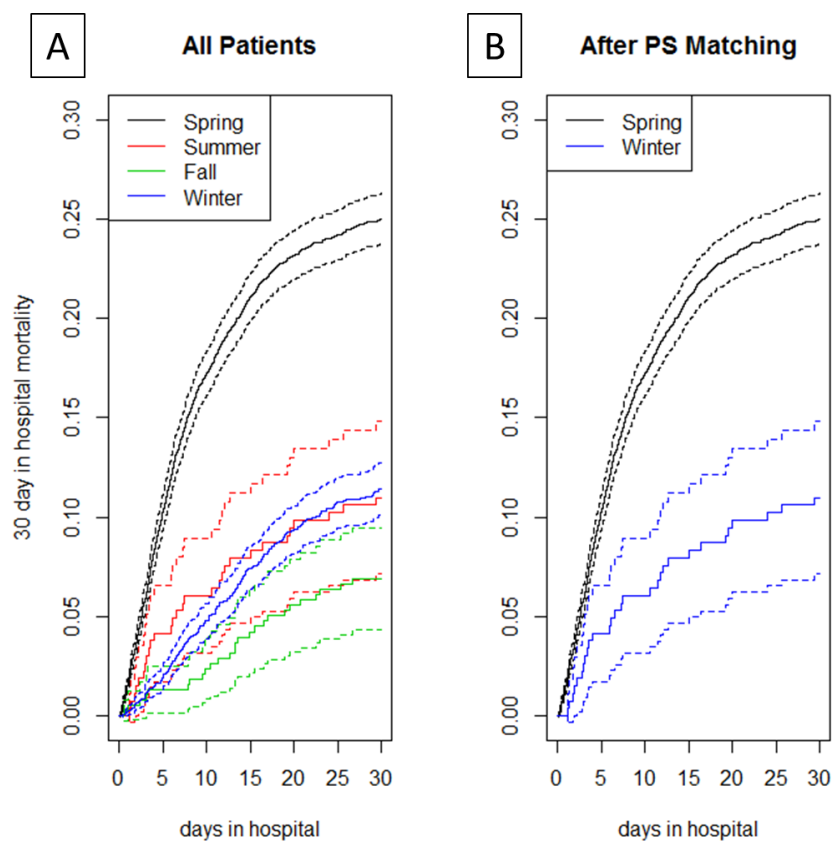

Figure 4 Cumulative incidence: 30-day in-hospital mortality (A) by season and (B) spring vs winter after propensity score matching. PS, propensity score.

in fall and $268(11.9 \%)$ in winter $(\mathrm{p}<0.001)$. The median time from arrival to intubation was 0.7 (0.1-4.1) days for spring patients, $0.6(0.1-8.1)$ days for summer patients, $2.2(0.1-7.3)$ days for fall patients and 2.8 (0.3-7.0) days for winter patients $(\mathrm{p}<0.001)$. The median length of stay was 6.1 (3.5-11.1) days during spring, 5.1 (2.7-10.1) days during summer, 5.0 (3.0-10.1) days during fall and 6.3 $(3.8-12.0)$ days during winter $(\mathrm{p}<0.001)$.

\section{Bed saturation and mortality}

We defined bed saturation as the percentage of bed occupancy calculated from the ratio between the number of admitted patients over the nominal bed capacity of our institution (1491).

In the multivariable competing risk proportional hazard model of the entire cohort, per cent of bed occupancy was associated with increased 30-day in-hospital mortality (HR 1.007, CI 1.001 to 1.013 , p=0.004); that is, mortality increases by $0.7 \%$ for each $1 \%$ increase in bed occupancy. Consistent results were observed per level increase in bed occupancy quartile (HR 1.086, CI 1.026 to 1.148 , p value for linear trend $=0.004)$. The results of the competing risk regression analysis are presented in table 2.

\section{Spring versus winter mortality comparison and propensity matched analysis}

In the multivariable competing risk proportional hazard model comparing spring and winter season, the 30-day in-hospital mortality was lower in winter (HR 0.520, CI 0.448 to $0.604, \mathrm{p}<0.001$ ) when compared with spring. After PS calliper matching, there were 1722 matched pairs. Spring and winter patients had similar distribution of PS (online supplemental figure 1) and the standardised average difference among covariates was greatly 
Table 2 Association with in-hospital mortality (regression models with competing risks)

\begin{tabular}{|c|c|c|}
\hline \multirow[b]{2}{*}{ Variable } & \multicolumn{2}{|l|}{ Multivariable } \\
\hline & HR $(95 \% \mathrm{Cl})$ & $P$ value \\
\hline Age, years & $1.046(1.04$ to 1.051$)$ & $<0.001$ \\
\hline Male sex, yes/no & $1.352(1.187$ to 1.54$)$ & $<0.001$ \\
\hline Body mass index, $\mathrm{kg} / \mathrm{m}^{2}$ & $1.022(1.012$ to 1.032$)$ & $<0.001$ \\
\hline Temperature, ${ }^{\circ} \mathrm{C}$ & 1.129 (1.063 to 1.200$)$ & $<0.001$ \\
\hline $\mathrm{SBP}, \mathrm{mm} \mathrm{Hg}$ & 0.994 (0.991 to 0.997$)$ & $<0.001$ \\
\hline $\mathrm{DBP}, \mathrm{mm} \mathrm{Hg}$ & $0.996(0.991$ to 1.001$)$ & 0.14 \\
\hline HR, beats per minute & $1.003(0.999$ to 1.006$)$ & 0.11 \\
\hline Oxygen saturation, \% & 0.967 (0.961 to 0.972 ) & $<0.001$ \\
\hline $\begin{array}{l}\text { Respiratory rate, breaths per } \\
\text { minute }\end{array}$ & 1.027 (1.019 to 1.035$)$ & $<0.001$ \\
\hline White cell count, $\times 10^{9} / \mathrm{L}$ & 1.008 (1.001 to 1.016$)$ & 0.02 \\
\hline Glucose, mg/dL & 1.001 (1 to 1.001$)$ & 0.001 \\
\hline $\begin{array}{l}\text { Aspartate aminotransferase, } \\
\text { U/L }\end{array}$ & $1(1$ to 1.001$)$ & 0.21 \\
\hline Alanine aminotransferase, $\mathrm{U} / \mathrm{L}$ & $1(0.999$ to 1$)$ & 0.25 \\
\hline Lactic acid, $\mathrm{mmol} / \mathrm{L}$ & $1.071(1.036$ to 1.107$)$ & $<0.001$ \\
\hline Platelet count, $\mathrm{k} / \mu \mathrm{L}$ & 0.999 (0.998 to 0.999) & $<0.001$ \\
\hline Potassium, mEq/L & 1.096 (1.028 to 1.168$)$ & 0.0052 \\
\hline Bicarbonates, mEq/L & 0.957 (0.944 to 0.971$)$ & $<0.001$ \\
\hline Creatinine, mg/dL & 1.023 (0.998 to 1.049$)$ & 0.069 \\
\hline HTN, yes/no & $1.008(0.851$ to 1.194$)$ & 0.93 \\
\hline HLD, yes/no & $1.196(1.02$ to 1.401$)$ & 0.027 \\
\hline CKD, yes/no & 1.263 (1.09 to 1.462$)$ & 0.002 \\
\hline HF, yes/no & 1.33 (1.146 to 1.543$)$ & $<0.001$ \\
\hline COPD/asthma, yes/no & $0.948(0.827$ to 1.088$)$ & 0.45 \\
\hline DM, yes/no & $0.946(0.819$ to 1.093$)$ & 0.45 \\
\hline CAD, yes/no & $1.101(0.955$ to 1.271$)$ & 0.19 \\
\hline Statin use, \% & 0.577 (0.501 to 0.664$)$ & $<0.001$ \\
\hline Bed occupancy, \% & 1.007 (1.001 to 1.013$)$ & 0.004 \\
\hline
\end{tabular}

CAD, coronary artery disease; CKD, chronic kidney disease; COPD, chronic obstructive pulmonary disease; DBP, diastolic blood pressure; DM, diabetes mellitus; HF, heart failure; HLD, hyperlipidaemia; HR, heartrate; HTN, hypertension; SBP, systolic blood pressure.

reduced. PS analysis showed a significant reduction in in-hospital mortality during winter (HR 0.580 , CI 0.507 to $0.663, \mathrm{p}<0.001$ ), confirming what we observed in the multivariable adjusted analysis (figure 4B).

\section{DISCUSSION}

We examined inpatient mortality from COVID-19 over the course of a 1-year pandemic at our hospital system in New York City. Our principal findings are as follows. First, we observed a substantial reduction in in-hospital mortality, coinciding with multiple pandemic-related public health measures focusing on hospital resource managementand preceding comprehensive changes in pharmacotherapy-towards the end of the first surge. Second, we describe for the first time hospital bed occupancy as an independent risk factor for inpatient mortality from COVID-19.

\section{Public health measures in response to COVID-19}

After declaring a state of disaster emergency (7 March 2020), New York State introduced different measures to limit the spread of the disease, including public school closures (16 March 2020), limitation in indoor dining (17 March 2020), stay-home order for non-essential workers (22 March 2020), mandatory face coverings in public (15 April 2020) and night subway closure (30 April 2020). ${ }^{24}$ Despite these measures to limit the diffusion of the disease and a generalised reduction of movements around New York City (as evidenced by a more than $90 \%$ reduction of subway ridership compared with 2019), ${ }^{25}$ more than $30 \%$ of Bronx residents were found to have positive antibodies (and thus possibly temporary immunity) against SARSCoV-2 in August 2020. ${ }^{26}$

Specifically relevant to hospital operations, executive order number 202.5 (16 March 2020) ${ }^{27}$ allowed healthcare providers not licensed or registered in New York State to temporarily work in the state, and executive order number 202.10 (22 March 2020) ${ }^{27}$ suspended elective operations. These executive orders were associated with a dramatic drop in non-COVID-19 admissions at our institution beginning 16 March 2020 (figure 1). On 26 March 2020 New York State Governor Cuomo additionally mandated all hospitals to increase their bed capacity by $50 \%$ to accommodate the surge of patients with COVID-19. ${ }^{27}$ Despite this order, the actual bed occupancy at our institution (while accommodating all patients with COVID-19 presenting to our hospitals) remained below the usual operating capacity until December 2020.

Notably, COVID-19 mortality remained stable throughout the summer and fall of 2020, with low case counts and increased utilisation of steroids, anticoagulation and remdesivir. Although randomised controlled trials have shown morbidity benefits with the use of remdesivir ${ }^{7}$ and mortality reduction with steroids, ${ }^{8}$ the magnitude of these effects cannot explain the more than $50 \%$ reduction in mortality we observed. Furthermore, pharmacotherapy, with the exception of hydroxychloroquine elimination, did not materially change within the spring season, by the end of which mortality was already decreased. Steroid, remdesivir and therapeutic anticoagulation were used in 10\%-20\% of patients by May 2020, but they reached $30 \%-70 \%$ only in the winter season. Despite this, unadjusted mortality began to increase again in December 2020 during the second wave. Of note, bed occupancy also increased at that time and proved to be an independent risk factor for COVID-19 mortality in our cohort of nearly 8000 patients.

\section{Change in therapeutic approach}

The initial widespread (more than two-thirds of first spring patients) use of hydroxychloroquine, an agent eventually proven to be ineffective ${ }^{28}$ to treat COVID-19, probably 
represents the most obvious pandemic-associated deviation from the usual multiphase clinical trial standards of therapeutic paradigm development. Only 8 of 2254 patients received hydroxychloroquine during the winter wave. Similarly, we observed a reduction in the use of azithromycin and other antibiotics, the latter possibly reflecting a more careful assessment of the need to treat superimposed bacterial infections during the second wave. Steroid therapy ${ }^{829}$ and therapeutic anticoagulation ${ }^{9}$ were implemented in the majority of patients during the winter after the knowledge on the likely disease modulating inflammatory proprieties and prothrombotic effect of COVID-19 had been recognised ${ }^{30}$ and, in the case of steroids, a therapeutic effect had been proven. ${ }^{8}$ Remdesivir, an inhibitor of the viral RNA-dependent RNA polymerase that showed shortening of recovery time in hospitalised patients with COVID- $19,{ }^{7}$ received emergency approval from the Food and Drug Administration on 22 October $2020^{31}$ and was administered to almost half of the admitted patients during the winter. If initial concerns of possible interactions between ACE-I or ARBs and SARS-CoV- $2^{32}$ led to a possible underutilisation or discontinuation of these drugs during the spring, we observed a significant increase in their use during the following months, after no increased risks were reported..$^{33} 34$

Similarly, after several reports showed a possible protective effect associated with the use of statins, ${ }^{35}{ }^{36}$ their utilisation markedly increased during the winter.

Lastly, after the spring wave provided anecdotal evidence for early proning in COVID-19 pneumonia, an approach strongly favouring non-invasive ventilation and avoiding intubation was developed to address respiratory distress in COVID-19; more data about such an approach have since accumulated. ${ }^{10} 37$ The cumulative effect of these therapeutic changes, in combination with a better preparedness to respond to a pandemic, can be estimate from the different mortality between the first surge (spring) and the second surge (winter). After matching the two groups in demographic and clinical variables, as well as in elements indicative of hospital distress (bed occupancy), a significant reduction in mortality was observed during the winter trimester.

\section{Change in hospital stress load}

At the peak of the pandemic, the hospital saturation reached the $118 \%$ of the nominal bed capacity and patients with COVID-19 accounted for $68.2 \%$ of all admitted patients. This increase in acutely ill patients created significant excess demand on the rest of the hospital infrastructure best characterised by the surge in the need for intensive care unit (ICU) beds and transformation of other hospital areas to ICUs. ${ }^{14} 23$ Despite increased patient load, the number of standard ICU beds, as well as laboratories, diagnostic equipment and available personnel, remained the same as before the pandemic. This unmatched patient overload resulted in a $0.7 \%$ mortality increase for each $1 \%$ increment in hospital bed saturation. In light of these results, strategies to minimise the bed occupancy for patients without COVID-19 or non-life-saving admission should be adopted to diverge resources to improve the outcome of admitted patients with COVID-19.

\section{Limitations}

Our study has the shortcomings of a retrospective investigation, but there are some very specific aspects limiting the interpretation of our results. First, it is difficult to assess the true effects of pharmacotherapy given the dynamic changes in indications, doses and usage that happened over the course of the year. Regardless, we believe the propensity matched comparison between the spring and the winter waves provides compelling evidence for the validity of our principal observation of inpatient COVID-19 mortality reduction disproportionate to advances in pharmacotherapy. We chose total bed occupancy as a metric for hospital stress assuming that other resources per bed remained static. Notably, the ratio of patients with COVID-19 to those without COVID-19, ICU bed saturation and staff shortages are unaccounted for in this model. Regrettably, an indepth analysis of these metrics is beyond our ability in this retrospective pandemic analysis with disaster elements. Additionally, a significant number of patients received ICU-level-of-care interventions (mechanical ventilatory support, dialysis, vasopressor titration) on regular floors; therefore, the concept of ICU bed saturation might have been not truly representative of the burden.

However, we feel our data are sufficiently strong to support the notion that bed capacity expansion alone is not the answer. Rather, a smaller number of beds with higher staffing accomplished by drastic reductions in all non-emergent procedures and activities is likely a better approach. Although offering fewer beds in a pandemic situation appears initially quite counterintuitive, in practice we observed that mortality began to decrease once beds and resources were allocated specifically to patients with COVID-19 by executive orders 202.5 and 202.10 , and most importantly that bed occupancy never exceeded $100 \%$ once hospital operations focused on the COVID-19 pandemic only. It is conceivable that an uptrend in mortality observed late in the pandemic with established treatment paradigms could be due to new viral strains or a sicker patient population. Although we are unable to provide detailed strain analysis for our study population, a meaningful number of new (and possibly more virulent) strains were not yet observed in the Bronx, where our study was conducted. ${ }^{38}$ The small sample size of patients in summer and fall does not allow meaningful propensity matched comparisons, and when comparing summer, fall and winter populations there do not appear to be clinically meaningful differences. Lastly, singlepatient data on vaccination status were not available. At the conclusion of the study, only $13.8 \%$ of the population of New York State have received at least one dose and $7.4 \%$ have received two doses. ${ }^{39}$ Given the heterogeneous distribution 
of vaccination within the state (and the city of New York), it is impossible to meaningfully account for these parameters.

\section{CONCLUSIONS}

Inpatient mortality from COVID-19 decreased to a degree disproportionate to advances in disease-specific therapeutics. Increased bed occupancy was associated with higher in-hospital mortality. Implementation of non-pharmacological approaches and other seasonal variations might also had a role in mortality reduction. Early reduction in epicentre hospital bed occupancy to accommodate acutely ill and resource-intensive patients should be a critical component in the strategic planning for future pandemics.

\section{Author affiliations}

${ }^{1}$ Albert Einstein College of Medicine, Bronx, New York, USA

${ }^{2}$ Division of Cardiology, Montefiore Medical Center, Bronx, New York, USA

${ }^{3}$ Department of Epidemiology and Population Health, Albert Einstein College of Medicine, Bronx, New York, USA

${ }^{4}$ Division of Cardiology, Massachusetts General Hospital, Boston, Massachusetts, USA

${ }^{5}$ Division of Infectious Diseases, Montefiore Medical Center, Bronx, New York, USA

${ }^{6}$ Department of Pediatrics, Montefiore Medical Center, Bronx, New York, USA

\section{Twitter Francesco Castagna @FraCastagna_MD}

Contributors Design of the project: $\mathrm{FC}, \mathrm{XX}$ and UPJ. Underlying data verification: FC, XX and UPJ. Acquisition, analysis and interpretation of data: FC, XX, OS, RK, YAP, SRP, MJG, ADR, DBS and UPJ. Statistical analysis: FC and XX. Obtained funding: UPJ. Manuscript writing: FC, XX and UPJ. Critical revision of the manuscript for important intellectual content: FC, XX, OS, RK, YAP, SRP, MJG, ADR, DBS and UPJ. Supervision: UPJ. Guarantor: UPJ.

Funding $\mathrm{FC}$ is supported by a grant from the National Institutes of Health (T32HL144456) and the National Center for Advancing Translational Science (NCATS) Clinical and Translational Science Award at Einstein-Montefiore (UL1TR001073). OS is supported by grants from the National Institutes of Health/ National Heart, Lung, and Blood Institute (K23HL145140) and the National Center for Advancing Translational Science (NCATS) Clinical and Translational Science Award at Einstein-Montefiore (UL1TR001073). UPJ is supported by the McAdam Family Foundation.

Competing interests None declared.

Patient consent for publication Not required.

Ethics approval The Office of Human Research Affairs at Albert Einstein College of Medicine approved this study (\#2020-11308). Patient consent and HIPAA forms were waived by our IRB due to the retrospective nature of our research.

Provenance and peer review Not commissioned; externally peer reviewed.

Data availability statement Data are available upon reasonable request. Request for de-identified data and dictionaries will be evaluated on a case-by-case basis after the submission of a research proposal to the corresponding author and the signature of a data access agreement. Data will be available after manuscript publication.

Supplemental material This content has been supplied by the author(s). It has not been vetted by BMJ Publishing Group Limited (BMJ) and may not have been peer-reviewed. Any opinions or recommendations discussed are solely those of the author(s) and are not endorsed by BMJ. BMJ disclaims all liability and responsibility arising from any reliance placed on the content. Where the content includes any translated material, BMJ does not warrant the accuracy and reliability of the translations (including but not limited to local regulations, clinical guidelines, terminology, drug names and drug dosages), and is not responsible for any error and/or omissions arising from translation and adaptation or otherwise.

Open access This is an open access article distributed in accordance with the Creative Commons Attribution Non Commercial (CC BY-NC 4.0) license, which permits others to distribute, remix, adapt, build upon this work non-commercially, and license their derivative works on different terms, provided the original work is properly cited, appropriate credit is given, any changes made indicated, and the use is non-commercial. See: http://creativecommons.org/licenses/by-nc/4.0/.

ORCID iD

Francesco Castagna http://orcid.org/0000-0002-8983-4866

\section{REFERENCES}

1 World Health Organization. WHO Director-General's opening remarks at the media briefing on COVID-19-11 March 2020. Geneva, Switzerland, 2020.

2 Bhatraju PK, Ghassemieh BJ, Nichols M, et al. Covid-19 in critically ill patients in the Seattle region - case series. N Engl J Med 2020;382:2012-22.

3 John Hopkins University. COVID-19 Dashboard by the center for systems science and engineering (CSSE) at Johns Hopkins University (JHU), 2020. Available: https://coronavirus.jhu.edu/map. html [Accessed 20 Jan 2021].

4 Lozano R, Naghavi M, Foreman K, et al. Global and regional mortality from 235 causes of death for 20 age groups in 1990 and 2010: a systematic analysis for the global burden of disease study 2010. Lancet 2012;380:2095-128.

5 Zhou F, Yu T, Du R, et al. Clinical course and risk factors for mortality of adult inpatients with COVID-19 in Wuhan, China: a retrospective cohort study. Lancet 2020;395:1054-62.

$6 \mathrm{Wu}$ Z, McGoogan JM. Characteristics of and Important Lessons From the Coronavirus Disease 2019 (COVID-19) Outbreak in China: Summary of a Report of 72314 Cases From the Chinese Center for Disease Control and Prevention. JAMA 2020;323:1239-42.

7 Beigel JH, Tomashek KM, Dodd LE, et al. Remdesivir for the Treatment of Covid-19 - Final Report. N Engl J Med 2020;383:1813-26.

8 RECOVERY Collaborative Group, Horby P, Lim WS, et al. Dexamethasone in hospitalized patients with Covid-19. N Engl J Med 2021;384:693-704.

9 Thachil J, Tang N, Gando S, et al. ISTH interim guidance on recognition and management of coagulopathy in COVID-19. $J$ Thromb Haemost 2020;18:1023-6.

10 Shelhamer MC, Wesson PD, Solari IL, et al. Prone positioning in moderate to severe acute respiratory distress syndrome due to COVID-19: a cohort study and analysis of physiology. $J$ Intensive Care Med 2021;36:241-52.

11 Rosenberg ES, Tesoriero JM, Rosenthal EM, et al. Cumulative incidence and diagnosis of SARS-CoV-2 infection in New York. Ann Epidemiol 2020;48:23-9.

12 Sekine T, Perez-Potti A, Rivera-Ballesteros O, et al. Robust T cell immunity in convalescent individuals with asymptomatic or mild COVID-19. Cell 2020;183:e14:158-68.

13 Fill Malfertheiner S, Brandstetter S, Roth S, et al. Immune response to SARS-CoV-2 in health care workers following a COVID-19 outbreak: a prospective longitudinal study. J Clin Virol 2020;130:104575.

14 Alvarez Villela M, Boucher T, Terre J, et al. Surge-in-Place: conversion of a cardiac catheterization laboratory into a COVID-19 intensive care unit and back again. J Invasive Cardiol 2021;33:E71-6.

15 Putter H, Fiocco M, Geskus RB. Tutorial in biostatistics: competing risks and multi-state models. Stat Med 2007;26:2389-430.

16 Gray RJ. A class of $\$$ K\$-sample tests for comparing the cumulative incidence of a competing risk. Ann Stats 1988;16:1141-54.

17 Fine JP, Gray RJ. A proportional hazards model for the Subdistribution of a competing risk. J Am Stat Assoc 1999;94:496-509.

18 Williamson EJ, Walker AJ, Bhaskaran $\mathrm{K}$, et al. Factors associated with COVID-19-related death using OpenSAFELY. Nature 2020;584:430-6.

19 Tartof SY, Qian L, Hong V, et al. Obesity and mortality among patients diagnosed with COVID-19: results from an integrated health care organization. Ann Intern Med 2020;173:773-81.

20 Schoenfeld D. Partial residuals for the proportional hazards regression model. Biometrika 1982;69:239-41.

21 Austin PC, Fine JP. Propensity-score matching with competing risks in survival analysis. Stat Med 2019;38:751-77.

22 Zhou B, Latouche A, Rocha V, et al. Competing risks regression for stratified data. Biometrics 2011;67:661-70.

23 Philips K, Uong A, Buckenmyer T, et al. Rapid implementation of an adult coronavirus disease 2019 unit in a children's Hospital. J Pediatr 2020;222:22-7. 
24 New York City Office of the Mayor. News. Available: https://www1. nyc.gov/office-of-the-mayor/news.page [Accessed 17 Jan 2021].

25 Metropolitan Transportation Authority. Fare data. Available: http:// web.mta.info/developers/fare.html [Accessed 17 Jan 2021].

26 New York City Department of Health and Mental Hygiene. COVID-19: data, 2021. Available: https://www1.nyc.gov/site/doh/covid/covid19-data.page [Accessed 17 Jan 2021].

27 State of New York. Executive orders. Available: https://www. governor.ny.gov/keywords/executive-order [Accessed 17 Jan 2021].

28 Cavalcanti AB, Zampieri FG, Rosa RG, et al. Hydroxychloroquine with or without azithromycin in mild-to-moderate Covid-19. N Engl J Med 2020;383:2041-52.

29 WHO Rapid Evidence Appraisal for COVID-19 Therapies (REACT) Working Group, Sterne JAC, Murthy S, et al. Association between administration of systemic corticosteroids and mortality among critically ill patients with COVID-19: a meta-analysis. JAMA 2020;324:1330-41.

30 Carsana L, Sonzogni A, Nasr A, et al. Pulmonary post-mortem findings in a series of COVID-19 cases from northern Italy: a twocentre descriptive study. Lancet Infect Dis 2020;20:1135-40.

31 United States Federal Drug Administration. FDA's approval of Veklury (remdesivir) for the treatment of COVID-19-The Science of Safety and Effectiveness. Available: https://www.fda.gov/drugs/drug-safetyand-availability/fdas-approval-veklury-remdesivir-treatment-covid19-science-safety-and-effectiveness [Accessed 17 Jan 2021].

32 Esler M, Esler D. Can angiotensin receptor-blocking drugs perhaps be harmful in the COVID-19 pandemic? J Hypertens 2020;38:781-2.
33 Mancia G, Rea F, Ludergnani M, et al. Renin-angiotensinaldosterone system blockers and the risk of Covid-19. N Engl J Med 2020;382:2431-40.

34 Zhang P, Zhu L, Cai J, et al. Association of inpatient use of angiotensin-converting enzyme inhibitors and angiotensin II receptor blockers with mortality among patients with hypertension hospitalized with COVID-19. Circ Res 2020;126:1671-81.

35 Tan WYT, Young BE, Lye DC, et al. Statin use is associated with lower disease severity in COVID-19 infection. Sci Rep 2020;10:17458.

36 Saeed O, Castagna F, Agalliu I, et al. Statin use and in-hospital mortality in patients with diabetes mellitus and COVID-19. J Am Heart Assoc 2020;9:e018475.

37 Paul V, Patel S, Royse M, et al. Proning in Non-Intubated (PINI) in Times of COVID-19: case series and a review. J Intensive Care Med 2020;35:818-24.

38 New York City Department of Health and Mental Hygiene. Health department releases detailed report on COVID-19 variants, 2021. Available: https://www1.nyc.gov/site/doh/about/press/pr2021/ health-department-releases-detailed-report-on-covid-19-variants. page [Accessed 12 Apr 2021]

39 New York City Department of Health and Mental Hygiene. COVID-19: Data - Vaccines: New York City Department of Health and Mental Hygiene, 2021. Available: https://www1.nyc.gov/site/ doh/covid/covid-19-data-vaccines.page\#dosestrend [Accessed 10 Dec 2021]. 